\section{Re: A Predictive Equation to Guide Vitamin D Replacement Dose in Patients}

To the Editor: Singh and Bonham's ${ }^{1}$ study concluded that a majority of patients require higher vitamin $\mathrm{D}$ treatment and maintenance doses than are currently recommended. Their statement regarding the need for higher vitamin D doses and serum concentrations is important, especially considering the morbidity and mortality that adequate vitamin $\mathrm{D}$ intake can prevent. Their statement claiming that sunscreen prevents the absorption of vitamin D from ultraviolet radiation, however, contradicts previously published studies.

Multiple studies found that typical sunscreen use does not limit the absorption of vitamin $\mathrm{D}$ to a clinically significant extent. Farrerons et $\mathrm{al}^{2}$ found that although vitamin $\mathrm{D}$ concentrations were lower in users of sun protection factor 15 versus placebo, concentrations were still sufficient to prevent a decrease in bone density or result in secondary hyperparathyroidism. Young ${ }^{3}$ found that adequate vitamin D concentrations were still obtained with appropriate sunscreen application despite higher vitamin D concentrations in nonsunscreen users. In addition, although sunscreen users' vitamin D concentrations did not increase during the study by Marks et al, ${ }^{4}$ they did remain within the therapeutic range and did not decrease. $^{4}$

Pharmacists and physicians should be aware that vitamin D supplementation beyond 800 IU is often necessary. Despite sunscreen use, patients can absorb vitamin D; therefore, supplementation and lifestyle modifications may work together to increase, or at least maintain, therapeutic concentrations of vitamin D. It is essential that pharmacists and physicians counsel patients on lifestyle opportunities, either in place of or in addition to supplementation with medication for patients who prefer nonmedication regimens, and for patients who need an additional boost in their vitamin $\mathrm{D}$ concentration despite recommended supplementation.

Janee B. Whitner, PharmD, RPh

ProMedica Toledo Hospital/W.W. Knight Family

Medicine Residency Toledo, $\mathrm{OH}$ janee.whitner@promedica.org

\section{References}

1. Singh G, Bonham AJ. A predictive equation to guide vitamin d replacement dose in patients. J Am Board Fam Med 2014; 27:495-509.

2. Farrerons, Barnadas, Rodríguez, et al. Clinically prescribed sunscreen (sun protection factor 15) does not decrease serum vitamin D concentration sufficiently either to induce changes in parathyroid function or in metabolic markers. Br J Dermatol 1998;139:422-7.
3. Young AR. Sun, sunscreens, and vitamin D. Poster presented at the meeting of the 4th International Anti-ageing Skin Care Conference, London, UK, June 2014.

4. Marks R, Foley PA, Jolley D, Knight KR, Harrison J, Thompson SC. The effect of regular sunscreen use on vitamin D levels in an Australian population: results of a randomized controlled trial. Arch Dermatol 1995;131:415-21.

doi: 10.3122/jabfm.2015.01.140230

The above letter was referred to the author of the article in question, who declined to comment.

\section{Re: Promotion of Family-Centered Birth With Gentle Cesarean Delivery}

Because we promote "gentle" cesarean delivery, ${ }^{1}$ I trust it is in the larger context $\mathrm{t}^{2,3}$ of avoiding cesarean delivery, ${ }^{4,5}$ whenever feasible, by "active conservative" management of labor (eg, partographs and decision making that considers alternatives to cesarean delivery). Through the American Academy of Family Physicians Advanced Life Support in Obstetrics ${ }^{6}$ course, family doctors are already leaders in this effort in the United States and abroad. ${ }^{7}$ This is likely already being done at Brown and other places where this advance in mother/child-centered birthing is working so well. If Magee et $\mathrm{al}^{1}$ could include the proportion of deliveries by cesarean delivery within their cohorts, this would frame that context.

Ronald E. Pust, MD

Department of Family Medicine and Public Health University of Arizona College of Medicine

Tucson, AZ rpust@email.arizona.edu

\section{References}

1. Magee SR, Battle C, Morton J, Nothnagle M. Promotion of family-centered birth with gentle cesarean delivery. J Am Board Fam Med 2014;27:690-3.

2. Torloni MR, Betran AP, Souza JP, et al. Classifications for cesarean section: a systematic review. PLoS One 2011;6: e14566.

3. Brennan DJ, Robson MS, Murphy M, O’Herlihy C. Comparative analysis of international cesarean delivery rates using 10-group classification identifies significant variation in spontaneous labor. Am J Obstet Gynecol 2009;201:308.e1-8.

4. Allen VM, O'Connell CM, Baskett TF. Cumulative economic implications of initial method of delivery. Obstet Gynecol 2006;108(3 Pt 1):549-5.

5. Ecker JL, Frigoletto. Cesarean delivery and the risk-benefit calculus. N Engl J Med 2007;356:885-8.

6. Dresang LT, Rodney WM, Leeman L, Dees J, Koch P, Palencia M. Advanced life support in obstetrics in Ecuador: teaching the teachers. J Am Board Fam Pract 2004;17: $276-82$. 